\title{
Influence of Temperature and Rainfall on the Phenology of Sclerocarya birrea (A. Rich) Hoscht in the Ferlo Zone (Senegal)
}

\author{
Awa Latyr Sène ${ }^{1,5}$, Aly Diallo ${ }^{2,5, *}$, Mariama Dalanda Diallo ${ }^{3,4,5}$, Moustapha Bassimbé Sagna ${ }^{1,5}$, \\ Ousmane Ndiaye ${ }^{4}$, Aliou Guisse ${ }^{1,4,5}$ \\ ${ }^{1}$ Department of Plant Biology, Cheikh Anta Diop University, Dakar, Senegal \\ ${ }^{2}$ Department of Agroforestry, Assane Seck University, Ziguinchor, Senegal \\ ${ }^{3}$ Aquaculture and Food Technologies, Gaston Berger University, Saint Louis, Senegal \\ ${ }^{4}$ Unité Mixte Internationale, Cheikh Anta Diop University, Dakar, Senegal \\ ${ }^{5}$ Centre National de la Recherche Scientifique, Dakar, Senegal
}

Email address:

aly.diallo@univ-zig.sn (A. Diallo)

${ }^{*}$ Corresponding author

\section{To cite this article:}

Awa Latyr Sène, Aly Diallo, Mariama Dalanda Diallo, Moustapha Bassimbé Sagna, Ousmane Ndiaye, Aliou Guisse. Influence of Temperature and Rainfall on the Phenology of Sclerocarya birrea (A. Rich) Hoscht in the Ferlo Zone (Senegal). American Journal of Agriculture and Forestry. Vol. 8, No. 5, 2020, pp. 181-189. doi: 10.11648/j.ajaf.20200805.11

Received: August 6, 2020; Accepted: August 18, 2020; Published: September 8, 2020

\begin{abstract}
The objective of this study was to characterize the phenology of the species Sclerocarya birrea (A. Rich) Hochst and to monitor the influence of climatic factors (rainfall and temperature) on its phenological behaviour. The study was carried out in three sites of Ferlo Nord (Senegal) (Amaly, Widou Thingoly and Tessekere) between December 2015 and December 2016. Climatic data were collected throughout the year and the phenological characterization of the species (leafing, flowering and fruiting) was carried out according to the method described by Grouzis \& Sicot in 1980. The results showed that for the majority of individuals, leaf fall was between August and March, the budding phase between January and July and full leafing between May and February. The flowering and fruiting phases took place during the dry period. There was also another flowering phase in the cold dry season, which was unusual for the species $S$. birrea. According to these observations the species behaved like a savannah species that flowers more than once a year. Marked differences were observed between and within sites for the leafing and flowering phases and a significant difference within and between species. Furthermore, the results confirmed the importance of inter-site variations and climatic variations in particular the temperature on $S$. birrea phenophases. The results of this study were of capital interest in the management and silviculture of this species whose potential was little exploited and less valued.
\end{abstract}

Keywords: Climatic Variability, Phenology, Sclerocarya birrea, Ferlo, Senegal

\section{Introduction}

Analysis of the phenology of plant species or formations had always provided important information on the impact of climate change on phytocenoses, but also on their consequences on ecosystem productivity $[1,2]$. According to Kouyaté, a better knowledge and a good programming of the harvesting periods of their organs required the control of their phenological cycle [3]. It was important to enhance the value of local forest species of interest for traditional pharmacopoeia, food, the use of wood as an energy source and fodder and craft use on local and regional markets in the face of the increased needs resulting from growing demographic pressure [3]. In the Sahelian zone, the study of the phenology of the woody stratum was motivated by practical reasons (determination of activity periods in order to specify its possible role in animal feed, productivity measurement, etc.) [2] and for more fundamental reasons 
(study of the relationship between cyclic changes in organ morphology and physiology and ecological conditions) [4]. In fact, beyond the interest of knowing the periods of availability of the species' resources, the phenological study was of undoubted importance as it enabled the impact of changes in reconstituted phytocenosis to be assessed over time [1, 2]. In Senegal, more precisely in the Ferlo area, Sclerocarya birrea (A. Rich) Hochst was planted in the framework of the reconstitution of degraded ecosystems, in the context of the establishment of the Great Green Wall to combat desertification [5]. It was therefore important to improve knowledge on the interactions between edaphoclimatic factors and the populations of S. birrea du Ferlo. Thus, several works had been carried out on the phenology of this woody species. These studies was initiated in Senegal [4], South Africa [6] and Burkina Faso [7, 8].

The aim of this work was to characterize the phenology of the species Sclerocarya birrea (A. Rich) Hochst and to monitor the influence of climatic factors (rainfall and temperature) on its phenological behaviour. Our study hypothesis was that this relationship contributed to a better understanding of the interactions between ecological factors and plants.

\section{Materials and Methods}

\subsection{Presentation of the Study Area}

The study was carried out in three sites in northern Senegal, in the commune of Tessekere (Louga region), in a Sylvopastoral zone commonly known as Ferlo (Figure 1). These are Amaly $\left(15^{\circ} 45^{\prime} 02.0^{\prime \prime} \mathrm{N}\right.$ and $\left.15^{\circ} 16^{\prime} 33.3^{\prime \prime} \mathrm{W}\right)$ in the South, Widou Thingoly $\left(15^{\circ} 56^{\prime} 02.5^{\prime \prime} \mathrm{N}\right.$ and $\left.15^{\circ} 11^{\prime} 43.1^{\prime \prime} \mathrm{W}\right)$ in the North-West and Tessékéré $\left(15^{\circ} 52^{\prime} 11.5^{\prime \prime} \mathrm{N}\right.$ and $\left.15^{\circ} 04^{\prime} 45.5^{\prime \prime} \mathrm{W}\right)$ in the East. Several reasons justify the choice of these sites: the presence of the species Sclerocarya birrea, an increasing rainfall gradient West-East and North-South [4, 2]. The sites was thus arranged along two axes:

1. West (W)-East (E): Widou Thiengoly-Tessekere;

2. North (N)-South (S): Widou Thiengoli-Amaly.

Ferlo belongs to the Sahelian climate, it was delimited by the 250-400 $\mathrm{mm}$ isohyets with two well marked seasons. The dry season lasted 9 months (November-June) and the rainy season lasted 3 months (July-October) with rainfall irregularly distributed in space and time [9, 2].
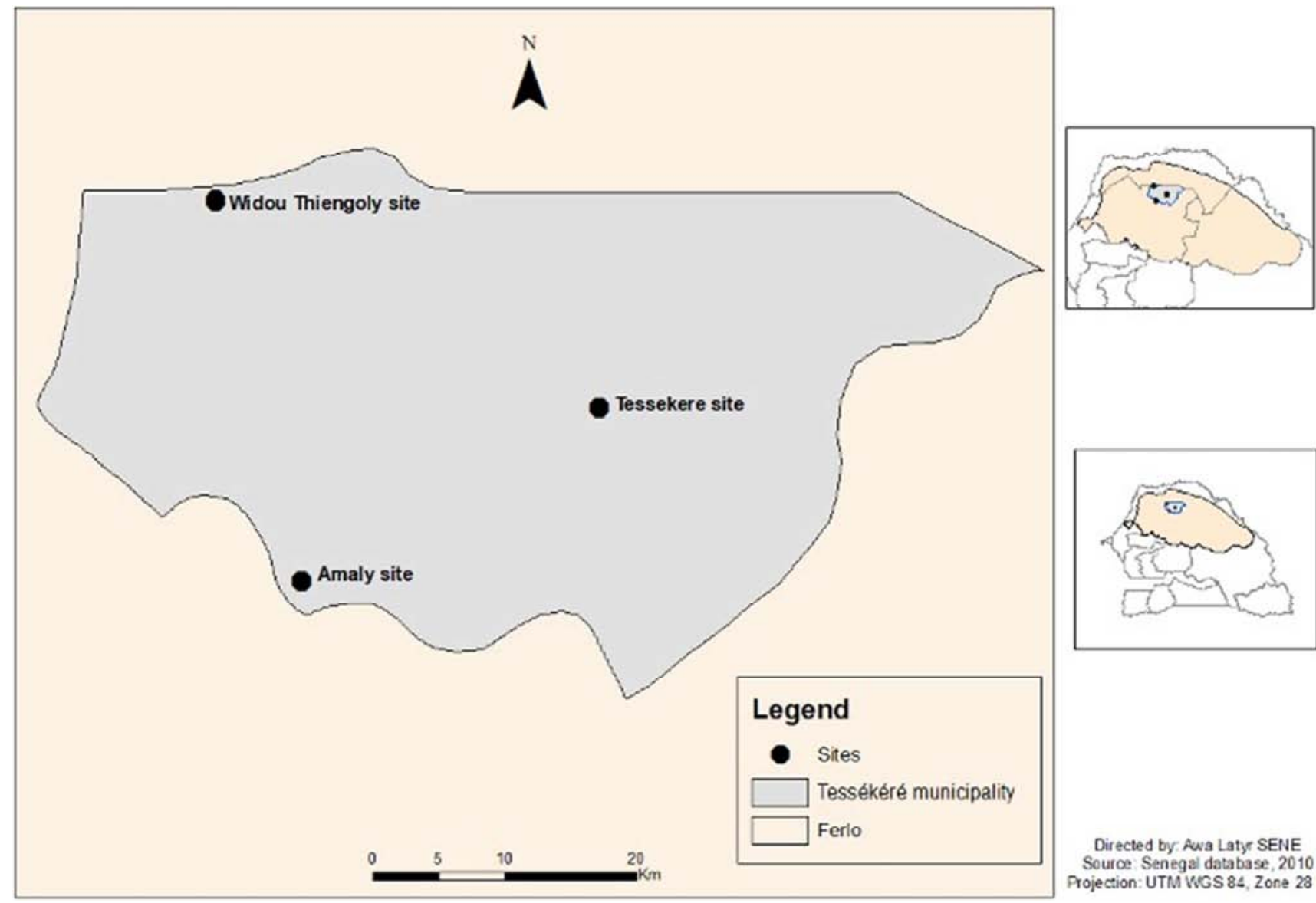

Figure 1. Study area location (source: Senegal 2010 database).

\subsection{Data Collection}

\subsubsection{Climatic Dato}

Climatic data were collected at the Linguere climate station by the National Meteorological Agency (ANACIM). The data were collected daily and a monthly average was calculated for both air temperature $(\mathrm{T})$ and rainfall $(\mathrm{R})$. 


\subsubsection{Phenological Data}

\section{Monitoring and sampling method}

The monitoring method used was inspired by that described by Grouzis and Sicot [10]. Observations were made on the different stages of leafing $(\mathrm{Fe})$, flowering $(\mathrm{Fl})$ and fruiting (Fr) of individuals at each site (Table 1). For a given site, the principle of phenological monitoring was to determine the average temporal course of development (appearance, flowering, decline) of individuals by observations at different dates, particularly concerning the development of organs such as leaves, flowers and fruits. In our case, a stratified sampling was carried out according to two topographic units (bottoms and flats) in our three stations. Individuals of reproductive age were selected and the sample was representative of the number of individuals per site. At the plateau level, we selected for Amaly (11), Widou (14) and Tessekere (23). At the lowland level, we also selected the same number of individuals: Amaly (11) and Widou (14); Tessékéré having no individuals at the lowland level, no individuals were selected. In total, seventy-three (73) individuals were followed between December 2015 and December 2016. This choice of high number of individuals allowed for the collection of the maximum amount of information on the target population [11].

Table 1. Stages and characteristics of the different observed phenophases [10].

\begin{tabular}{lll}
\hline Phenophases & Stages & Caractéristiques des stades phénologiques \\
\hline & 0 & Bare and leafless branches \\
Leafing $(\mathrm{Fe})$ & 1 & Leaf buds, unfolded leaves \\
& 2 & Leaves flourishing and abundant on the twigs \\
& 3 & Leaf senescence and leaf fall \\
& 0 & No flowers on the tree \\
Flowering (Fl) & 1 & Floral sketches and some blooms \\
& 2 & Full bloom and abundance of flowers \\
& 3 & Fading flowers with falling floral pieces \\
& 0 & No fruit on the tree \\
& 1 & Appearance of young fruits \\
Fruiting $(\mathrm{Fr})$ & 2 & Ripeness and abundance of fruit \\
& 3 & Fall of the fruits \\
\hline
\end{tabular}

Periodicity and conduct of phenological observations

The frequency of phenological surveys is monthly. The

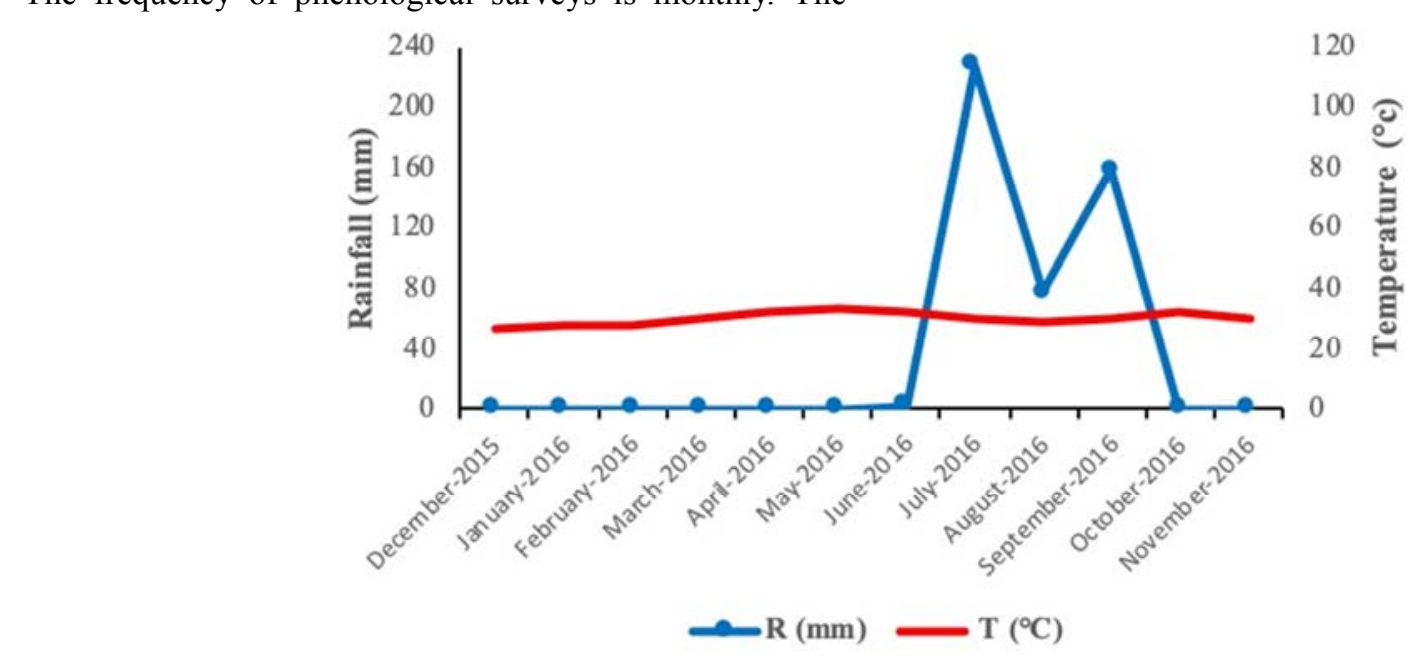

Figure 2. Ombrothermal Diagram of the 2016 Study Area. observation period was three days due to the high number of individuals to be sampled and the distance between the different sites. The monitoring plots were geo-referenced and the individuals were marked and numbered with paint. Observations were visual. Phenological stages were recorded in a phenological monitoring sheet.

\subsection{Data Processing and Analysis}

All phenological data were presented in percentage and graphical form. The phenological spectrum was constructed by calculating, for each date of observation of frequencies within the population, the individuals in the leafing (Fe \%), flowering (Fl \%) and fruiting (Fr \%) phase was calculated using the following formula [10]:

$$
\mathrm{F}=\mathrm{n} / \mathrm{N} \times 100
$$

with, F (\%): percentage of individuals of the site present at the various phases of leafing, flowering or fruiting;

$\mathrm{n}$ : number of individuals of the same species at a given phenological stage;

$\mathrm{N}$ : total number of individuals (population size).

The influence of climate on the different phenophases was analysed by correlation with climatic parameters.

\section{Results}

\subsection{Ombrothermal Diagram of the Study Area}

The analysis in Figure 2 showed two periods of successive bioclimatic events; a long dry season (October-June) followed by a period of high humidity (July-September). Further analysis had allowed us to divide the year into three very remarkable seasons:

1. a cool dry season from October to February with relatively low temperatures;

2. a dry and hot season from March to June characterized by high temperatures;

3. a wet season from July to September characterized by high rainfall. 


\subsection{Evaluation of Phenological Phases}

\subsubsection{Leafing}

The monitoring of twig budburst had made it possible to assess the period of early vegetative growth (Figure 3 ). This leafing process began in late January with the appearance of buds and took place in July. And a resumption was noted immediately afterwards in late August and ends in midDecember at Amaly and Tessekere, while it took place earlier in February at Widou. Full leafing (Fe2) extended from May to January at Amaly and Widou. On the other hand, at

A

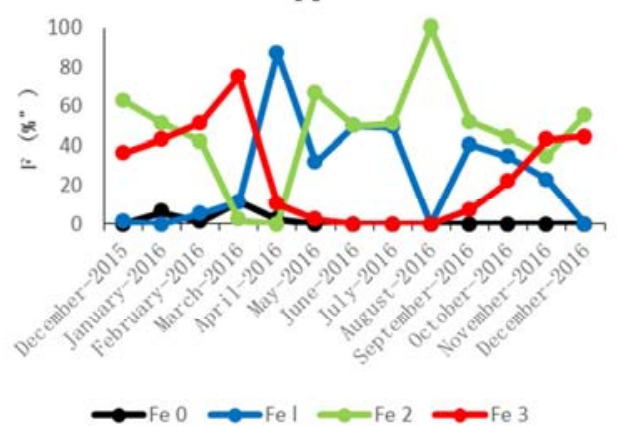

C

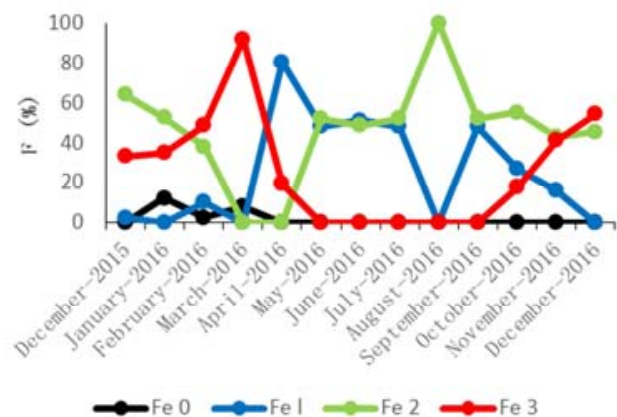

Tessekere, we noted a delay in October. Indeed, the amplitude of this phase was observed in August in all sites and almost $100 \%$ of the individuals are in full foliage. Leaf fall occured for most individuals in late August, which was the month when leaf fall was at its peak in Tessékéré and Amaly sites. And in November nearly $45 \%$ of the individuals were in full leaf fall. On the other hand, leafing began earlier in late September at Widou. In March more than $90 \%$ of the individuals were in total leaf removal at Widou.

Figure 3. Leaf phenology of S. birrea in the study area and at the sites (A: Study area; B: Amaly; C: Widou; D: Tessekere) (Fe1=early leafing; Fe2=full leafing; $\mathrm{Fe} 3=$ =late leafing; $\mathrm{Fe} 0=$ total defoliation).

\subsubsection{Flowering}

Analysis of Figure 4 shows that most individuals started flowering between late February (end of the cold dry season), early March and end early July. However, another flowering phase was observed respectively between October and

A

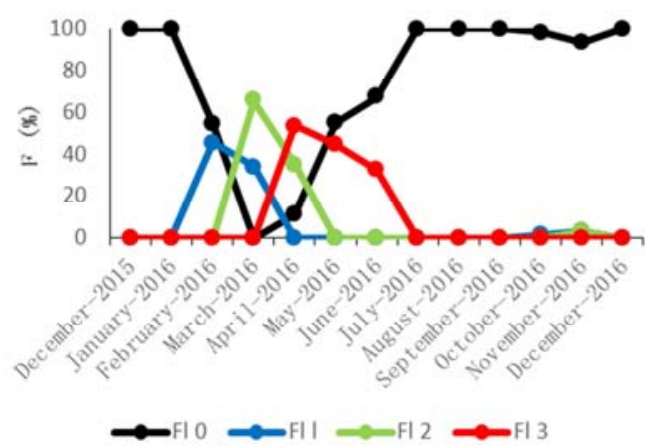

December at Amaly, between August and December at Tessekere and in November at Widou. Full flowering took place between March and April. But this resumption of flowering concerned less than $10 \%$ of the individuals. The end of flowering was observed in July.

$$
\text { B }
$$

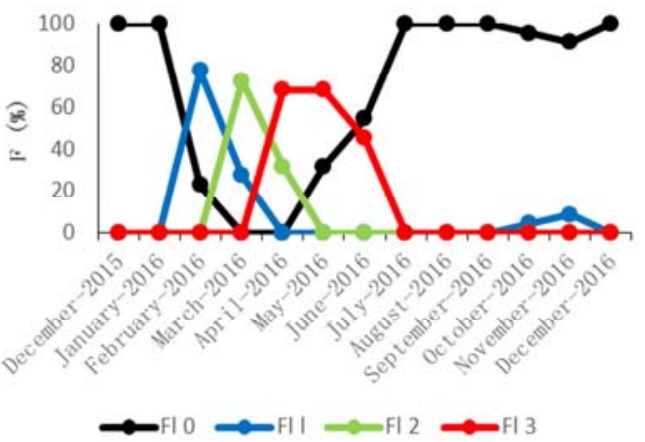


C

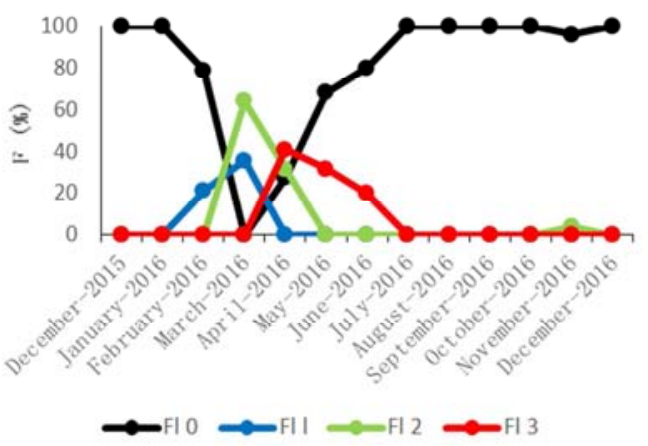

D

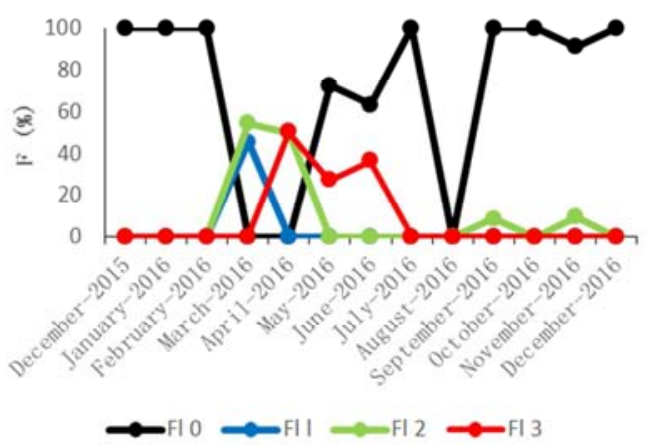

Figure 4. Flowering spectrum of S. birrea in the study area and at the sites (A: Study area; B: Amaly; C: Widou; D: Tessekere) (Fll=beginning of flowering; Fl2 =full flowering; Fl3=end of flowering, FlO=individuals without flowers).

\subsubsection{Fructification}

Analysis of the fruiting patterns (Figure 5) showed that individuals were fruiting between the months of February and July. In June, more than $53 \%$ of the individuals were in full fruiting. Ripening and abundance of fruit in Amaly were

A

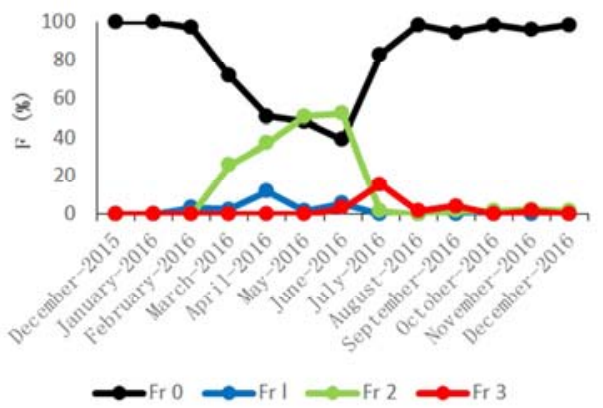

C

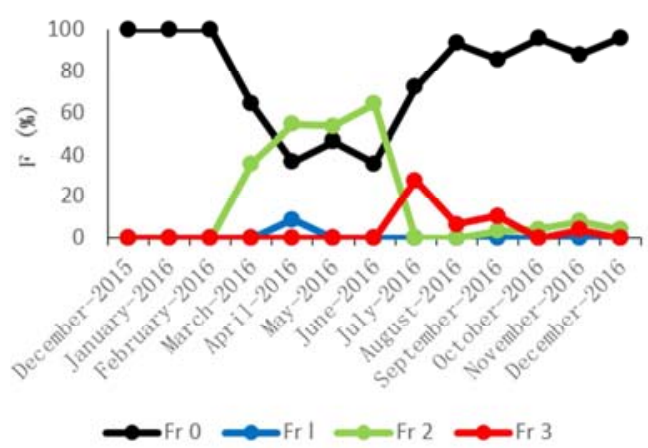

observed during June, while in Widou and Tessékéré it took place in July. In Widou, a second fruiting was observed at the end of the rainy season and the beginning of the dry season between September and December, but only less than $10 \%$ of the individuals were concerned.

B

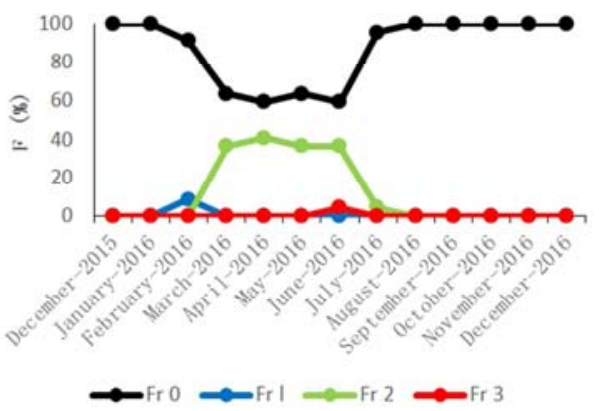

D

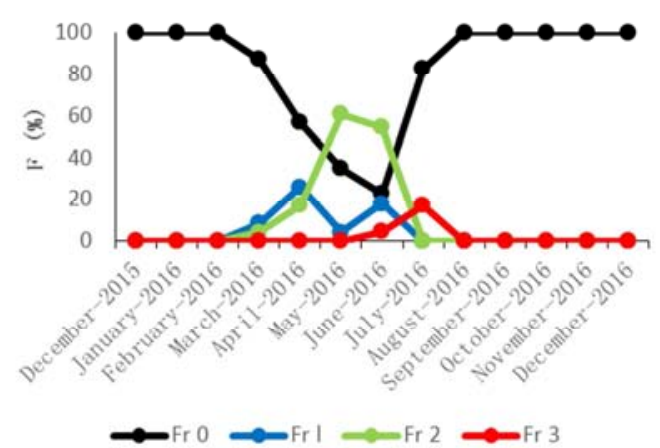

Figure 5. Fruiting spectrum of S. birrea in the study area and at the sites (A: Study area; B: Amaly; C: Widou; D: Tessekere) (Fr1=early fruiting; Fr2=full fruiting; $\mathrm{Fr} 3=$ late fruiting; $\mathrm{Fr} 0=$ fruitless individuals).

\subsection{Influence of Temperature and Rainfall on Phenology Sclerocarya Birrea}

\subsubsection{Influence of Temperature and Rainfall on Leafing}

Figure 6 showed that the leafing process of S. birrea begins in March-April with bud emergence (hot dry season) and ends in January with complete leaf fall (cold dry season). However, the appearance of buds took place during the hot dry season between March and June, a period characterized by high temperatures, which implied that rainfall was not a determining factor at this stage. These results showed that $\mathrm{S}$. birrea waited until the end of the cool dry season before starting to leaf out. In the cool dry season, the species showed a growth arrest. This standstill corresponded in principle to the period of low temperatures and low light intensities. And the duration of full foliage was 9 months (May-January). This indicated that full foliage was more spread out. The trees entered full leaf in May, which was 
mainly characterised by an average monthly temperature of more than $30^{\circ} \mathrm{C}$. Furthermore, the species' full foliage was

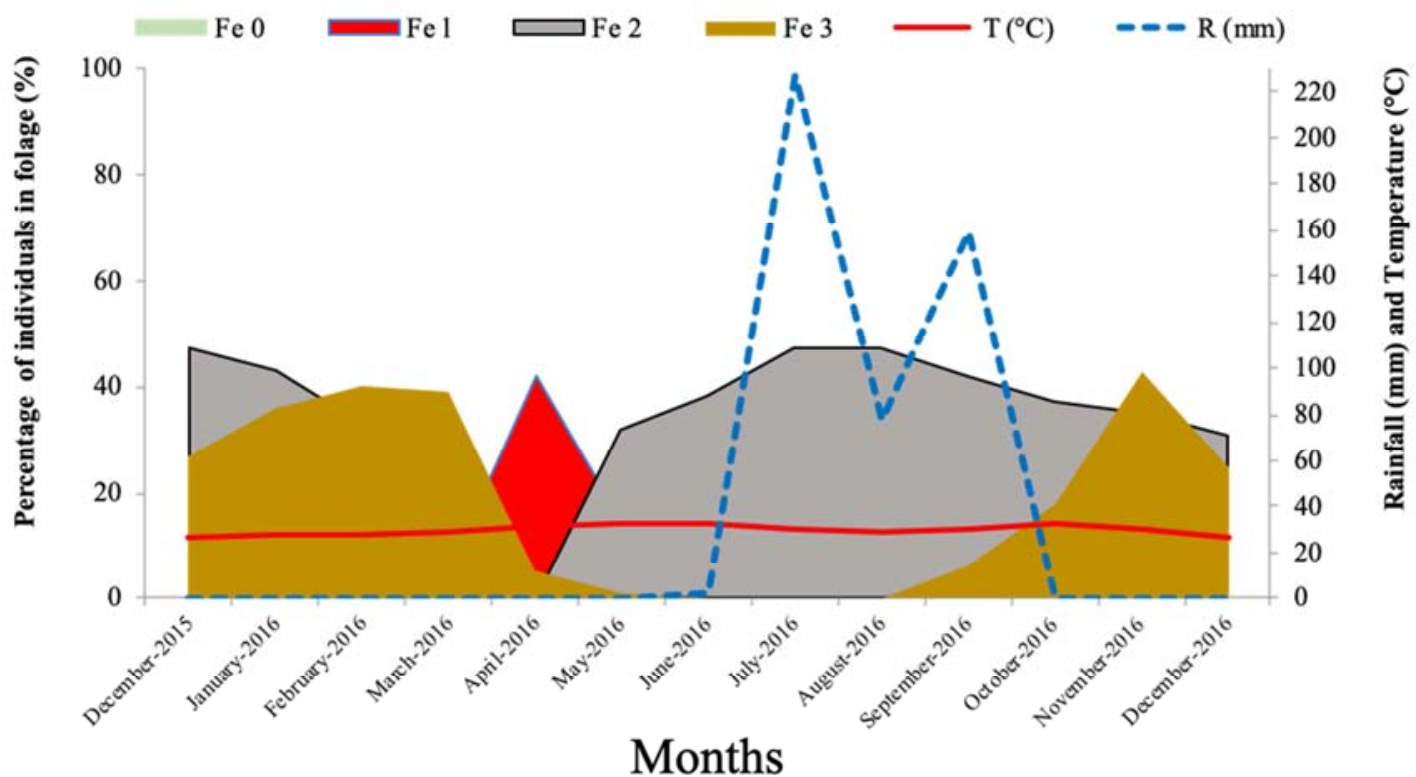

Figure 6. Influence of Rainfall and Temperature on Leafing.

\subsubsection{Influence of Temperature and Rainfall on Flowering}

Flowering begins in late February (end of the cool dry season), early March and ends in early July in the study area (Figure 7). Full flowering proper lasts two months between
March and April. It takes place, therefore, in the hot dry season characterized by high temperatures. This also implies that rainfall is not a determining factor at this stage, as it is for leafing.

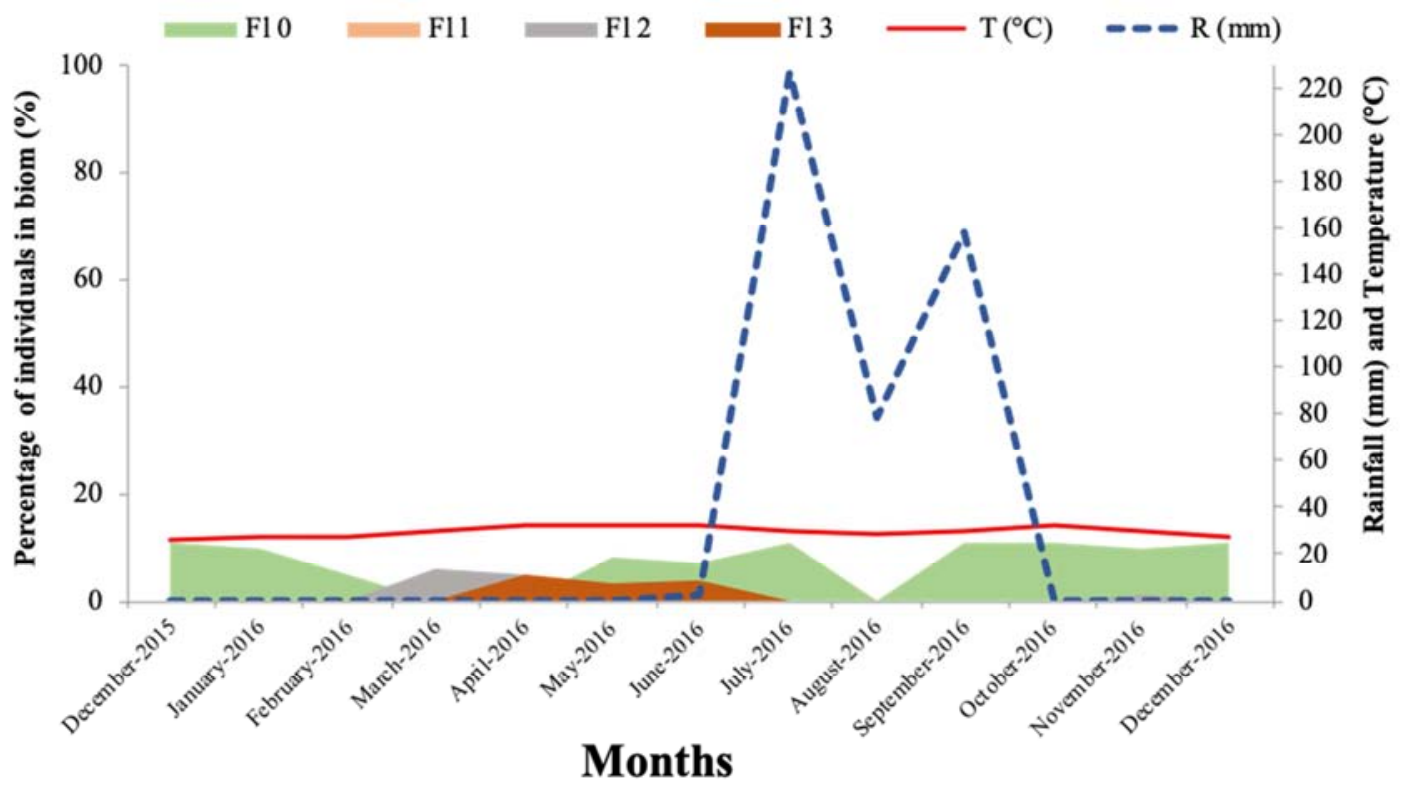

Figure 7. Influence of rainfall and temperature on flowering.

\subsubsection{Influence of Temperature and Rainfall on Fructification}

The fruiting process of $S$. birrea began towards the end of March (Figure 8). Observation of the fruiting spectra showed that full fruiting took place between the end of April and the end of June. Ripening and fruit drop took place between June and August. This stage was in the rainy season with monthly rainfall ranging from $227.4 \mathrm{~mm}$ to $77.9 \mathrm{~mm}$. These results indicated that fruit ripening occured when new leaves appeared and others in full foliage in some individuals where temperatures were at their highest (average $30^{\circ} \mathrm{C}$ ). 


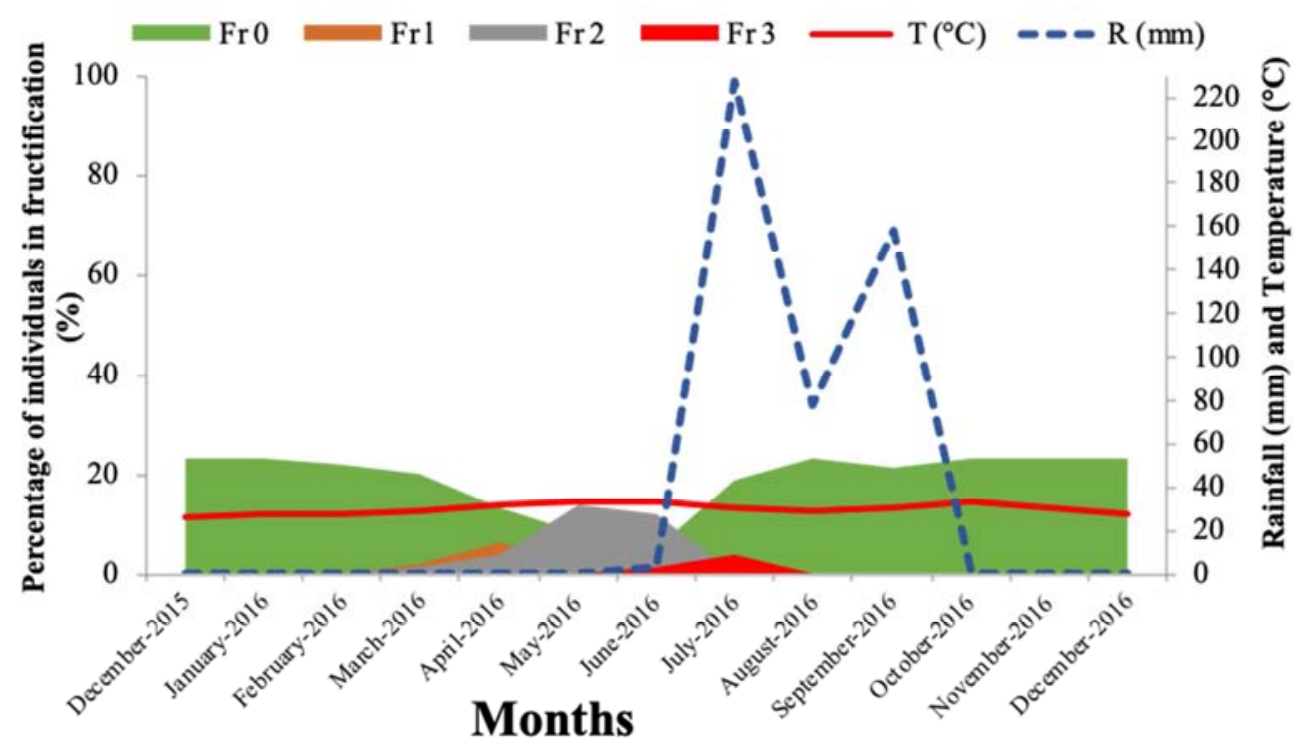

Figure 8. Influence of rainfall and temperature on fructification.

\section{Discussion}

The results of the phenological study of S. birrea showed inter-population variability for the duration of the leafing, defoliation and fruiting process. The leafing process began at the end of the hot dry season with bud emergence and ends in the cool dry season with total leaf fall at our three sites. A resumption was noted immediately afterwards in September and ends in December at Amaly and Tessekere, while it took place earlier in February at Widou. However, this resumption of foliage was rapid with the return of the rains. In the Sahelian zone, Poupon noted a relationship between leaf budburst and the rise in relative humidity at the end of the dry season [12]. For some species, leaf bud dormancy was rather lifted by the photoperiod through the appearance of long days [13]. This could be explained by the formation of new leaves in some individuals when the fall of the old ones was not yet complete. The appearance of young leaves in the dry season was an unusual occurrence in most woody species and was thought to be due to the use of water from deep soil layers [14]. The leaf break observed at the end of the dry season was similar to that observed by Poupon [12]. Thus, leaf and blossom setting seemed to be independent of water availability in the soil surface horizons. According to our results, the leafing and flowering phases were mainly dependent on temperature, as the increase of this parameter allows the start of leafing and flowering. On the other hand, foliage and flowering were not directly dependent on rainfall and the number of rainy days. However, the earliness of foliar budburst observed in Widou individuals can be explained by studies $[15,16]$, which stipulate that the influence of age on budburst was more likely to occur in young plants than in adult trees. Full leafing of S. birrea lasted 9 months. These results corroborated to the observations of Poupon [12]. Leaf optimum was observed from the rainy to the dry season in a study of B. aegyptiaca [2]. This meaned that this stage took place mainly during the rainy season where the species probably develops mechanisms to take advantage of the high relative humidity of the air due to increased temperatures and rainfall. For others, the reduction of water loss due to leafing on the one hand, and the absorption of water by the roots on the other, ensured rehydration of the plants, thus triggering leafing [17, $18]$.

As far as flowering was concerned, it took place between the end of February (end of the cool dry season), the beginning of March and ends at the beginning of July. However, our results showed that the phases of leafing and flowering depended on temperature and humidity because the increase of these parameters allows the start of leafing and flowering. Our results showed that this phenophase occured in most individuals when they were in the foliar budburst or late foliage phase. However, differences between sites were very small. Populations of the species flowered almost simultaneously at all sites. On the other hand, another flowering phase was observed respectively between October and December at Amaly, between August and December at Tessékéré and in November at Widou. Full flowering takes place between March and April. However, another flowering phase in the cool dry season was unusual for S. birrea. But this resumption of flowering only concerned less than $10 \%$ of the individuals. Our observations showed that the species behaved like a savannah species that flowered more than once a year. Some authors cited as examples Acacia senegal (L.) Willd. (Fabaceae), Anogeuis leiocarpus and Balanites aegyptiaca (L.) Del. (Balanitaceae), respectively [12, 19]. This phase was not followed by fruiting in Amaly and Tessekere. This could be explained by the low temperatures and low light intensities that characterized this season or it could be due to the use of water from deep soil layers [14]. In 2015, Sagna had noticed that moisture is a factor influencing the flowering rate of the plant. Full flowering lasted one month between March and April. It took place, therefore, in the hot dry season characterized by high temperatures, 
insulation and evaporation. This meaned that rainfall was not a determining factor at this stage. However, some studies placed its flowering process between April and August [4], which was invalidated by the present study carried out in Senegal. From a physiological point of view, this flowering peak occured during the longest period of insolation of the year (more than 250 hours). This showed that photoperiodism was a determining factor in the flowering of the species, as was the case for most woody plants [20]. Other factors inherent to the species could influence its flowering, as never all the individuals monitored had flowered at the same time under identical ecological conditions. These variabilities could reflect a high degree of genetic heterogeneity within the species' population [21], as had been well articulated in previous studies [22].

In addition, fruiting began around February. Observation of the fruiting spectra shows that full fruiting took place between the end of April and the end of June. Ripening and fruit drop took place in June-August. These results indicated that fruit ripening occured at the time of new leaf emergence and leaf fall in some individuals [4]. We also noted that between individuals of the same population, the time lag between different phenophases could reach one month. Ripening and fruit abundance at Amaly, were observed during one month (June), while at Widou and Tessekere, it took place in July. In Widou, a second fruiting was observed at the end of the rainy season and the beginning of the dry season between September and December. Indeed, within the same population, this stage seemed to be variable from one station to another and even from one individual to another [2].

The development of the different phenological phases, in particular the beginning of leafing and flowering, took place in the dry season. During this season, water reserves could be at their minimum level. A major contribution of the root pivot to water supply was noted when surface water reserves were exhausted [23]. Nevertheless, it should be noted that further analyses of these phenological diagrams had shown an overlap of intermediate stages over time. New leaves were formed in some individuals while the old ones were still falling. A fairly staggered flowering phase seems to be variable from one station to another and even from one individual to another and within the same population. These results confirmed those of [4] in a phenological study on the same species. However, a shift could often occur even within the same population. This shift could occur as a result of fluctuations in climatic and edaphic factors [25]. In addition, the foliage started to leaf out at the end of the dry season while the tree was still bearing some fruit. And by the time the flowers appeared in the middle of the dry season some of the trees are leafless or at the beginning of leafing. The end of fruiting (Fr3) had also been very spread out. It was sometimes very difficult to observe, because some individuals bore two generations of fruit at the same time. These differences could be explained by variability between individuals [24]. This intraspecific variability could be the response of the organism, within the limits set by its genotype, to fluctuations in environmental factors (e.g. spatial heterogeneity of the substrate), or on the contrary the result of genotypic differentiation $[25,26]$.

\section{Conclusion}

Our results showed a significant intra- and interspecific difference in the species S. birrea. Marked differences were observed between and within sites for the leafing and flowering phases. However, our results showed that another flowering phase in the cool dry season is unusual for $\mathrm{S}$. birrea. According to these observations the species behaved like a savannah species that flowers more than once a year. Moreover, the results of the study confirmed the importance of inter-site and climatic variations, especially temperature on the phenophases of S. birrea. The results of this study were of capital interest in the management and silviculture of this species whose potential was little exploited and less valued.

\section{Acknowledgements}

This work has benefited from State aid managed by the National Research Agency under the LabEx DRIIHM, "Investments in the future" programme bearing the reference ANR-11-LABX-0010 and the laboratory Unite mixte Internationale (UMI3189 "Environnement, Santé, Sociétés" Université Cheikh Anta Diop-UCAD).

\section{References}

[1] Jaouadi W., Hamrouni L., Khouja M. L., 2012. Phenology of Acacia tortilis subsp. raddiana in the Bou Hedma National Park in Tunisia, effect of the site on the Phenophases of the species. Bois \& Forêts Des Tropiques, n 312 (2), 9 p.

[2] Sagna M. B., 2015. Ethnobotany, ecology, phenological monitoring and physico-chemical and nutritional characteristics of the desert date palm (Balanites aegyptiaca (L.) Del.) in the Ferlo in northern Senegal. Unique thesis in biodiversity and environment specialization knowledge, conservation and management of biodiversity, Senegal. $113 \mathrm{p}$.

[3] Kouyaté A., 2005. Ethnobotanical aspects and study of the morphological, biochemical and phenological variability of Detarium microcarpum Guill. \& Perr. in Mali. Thesis of Doctor (Ph. D) in Biosciences Engineers Section Agronomy. 207 p.

[4] Diallo M. D., Saleh M. M., Diallo A., Bassene C., Ndiaye O., Niang K., Diop A., Guisse A., 2016. Characterization of the variability of the phenophases of five Sahelian plant species in the northern zone Ferlo, Senegal. Rev. Ivoir. Sci. Technol., 27: $117-135$.

[5] Ndiaye O., Diallo A., Wood S. A., Guisse A., 2014. Structural Diversity of Woody Species in the Senegalese Semi-Arid ZoneFerlo. American Journal of Plant Sciences, 5, 416 -426. 11 p.

[6] Leakey R., Pate K., Lombard C., 2005. Domestication potential of marula (Sclerocarya birrea subsp. caffra) in South Africa and Namibia: 2. phenotypic variation in nutand kernel traits. Agroforestry systems, 64, 37-49. 
[7] Hall J. B., O'Brien E. M., Sinclair F. L., 2002. Sclerocarya birrea: a monograph (Vol. 19). University of Wales, Bangor. School of Agricultural and Forest Sciences. $157 \mathrm{p}$.

[8] Muok B. O., Khumalo G. S., Tadesse W., Alem S. h., 2011. Sclerocarya birrea, conservation and sustainable use of genetic resources of priority food woody species in subSaharan Africa. Rome, Bioversity International $12 \mathrm{p}$.

[9] Trochain J., 1940. Contribution to the study of vegetation in Senegal. Mem. IFAN, no 2, $433 \mathrm{p}$.

[10] Grouzis M., Sicot M., 1980. A method for the phenological study of populations of Sahelian woody species: influence of some ecological factors. In: Le Houérou H. N. (ed.). Woody fodder in Africa: current state of knowledge. Addis Ababa, Ethiopia, Cipea, pp. 231-237.

[11] Grouzis M., 1993. Phenology of two Sahelian woody species: methodological aspects and influence of environmental factors on the environment (seminar Paris- Nancy, France from 20 March to 6 April 1990). Ed. A. Riedacker et al. pp. 145-15

[12] Poupon H., 1979. Study of the phenology of the woody stratum in Fété-Olé (northern Senegal) from 1971 to 1977. Bull. IFAN, Ser. A. 41 (1): 44-85.

[13] Kramer P. J., Kozlowski T. T., 1960. Physiology of trees. New York, États-Unis, McGraw-Hill Book Company, 642 p.

[14] Zoungrana C. K., Diarra B., Adandedjan C., Savadogo S., 2008. Nutritional value of Balanites aegyptiaca for ruminant feed. Livestock Research for Rural Development, 20 (4), 15 p.

[15] Galoux, A., 1966. The genecological variability of common beech (Fagus silvatica L.) in Belgium. Groenendaal Water and Forest Research Station-Hoeilaart. Works Series A, 11, $123 p$.

[16] Beuker E., 1994. Adaptation to climatic changes of the timing of bud burst in populations of Pinus sylvestris L. and Picea abies (L.) Karst. Tree Physiology, 14 (7-9), 961-970.

[17] Borchert R., 1994a. Water storage in soil or tree stems determines phenology and distribution of tropical dry forest trees. Ecology, 75 (5): 1437-1449.
[18] Borchert R., 1994b. Water status and development of tropical trees during seasonal drought. Trees, 8 (3): 115-125.

[19] Seghieri., J. (1990). Dynamique saisonnière d'une savane soudano-sahélienne au nord Cameroun. Thèse. Acad. Montpellier. Univ. Montpellier II. 200.

[20] Chapman C. A., Wrangham R. W., Chapman L. J., Kennard D. K., Zann A. E., 1999. Fruit and flower phenology at two sites in Kibale National Park, Uganda. Journal of Tropical Ecology, 15: 189-211.

[21] Arbez M., 1969. Comparative study in nurseries of some French provenances of pectin fir (Abies alba Mill.). First overview of infraspecific variability and focus on the "Aude fir". Annales des Sciences Forestières, 26 (4), 475-509.

[22] Chevallier., M. H., Bensaid S., Diallo O. B., Sahki R., Ganaba S., Sanou J., Bouguedoura N., Vaillant A, Babin D (2003). Biodiversity and multidisciplinarity: methodology for drylands. Bois \& Forets des Tropiques, 276 (2): 33-41.

[23] Do F., Rocheteau A., Diagne A. L., Grouzis M., 1998. Sap flow and water consumption of Acacia tortilis in Northern Ferlo. In: Campa C., Grignon C., Gueye M., Hamon S. (eds). Acacia in Senegal. Paris, France, Orstom, coll. Colloquia and seminars, pp. 64-80.

[24] Piot J., Nebout J. P., Nanot R., Toutain R., 1980. Use of Sahelian woody plants by domestic herbivores S: quantitative study in the southern zone of the Mare d'Oursi (Upper Volta). Paris, France, Centre technique forestier tropical, Institut d'élevage et de médecine vétérinaire des pays tropicaux. 304 p.

[25] Grouzis M., Albergel J., 1991. From climatic risk to ecological constraint: Impacts of drought on crop production and the environment in Burkina-Faso. In: ELDIN and MILLEVILLE (Eds.), Le risque en agriculture 243-254, ORSTOM éd., Paris.; 620 p.

[26] Msukwa V. J., Munthali C. R. Y., Nyoka B. I., Missanjo E., 2019. Phenology of Sclerocarya birrea (A. Rich.) Hochst. Provenances. Emerging Science Journal, Vol. 3, N . 1, 10-22. 